\title{
Configurações
}

Revista Ciências Sociais

$25 \mid 2020$

Debater o desenvolvimento: questões, dilemas e alternativas

\section{Notas sobre cooperativismo, gestão rural, e bem viver na Amazônia: estratégias de resistência ao capitalismo}

Notes on Cooperativism, Rural Management, and Good Living in Amazonia:

Strategies for Resisting Capitalism

Notes sur le coopérativisme, la gestion rurale et le bien-vivre en Amazonie:

stratégies de résistance au capitalisme

Antônio Carlos Witkoski, Marília Gabriela Gondim Rezende e Therezinha de Jesus Pinto Fraxe

\section{OpenEdition}

Journals

Edição electrónica

URL: http://journals.openedition.org/configuracoes/8562

DOI: 10.4000/configuracoes.8562

ISSN: 2182-7419

\section{Editora}

Centro de Investigação em Ciências Sociais

\section{Edição impressa}

Paginação: 88-96

ISSN: 1646-5075

\section{Refêrencia eletrónica}

Antônio Carlos Witkoski, Marília Gabriela Gondim Rezende e Therezinha de Jesus Pinto Fraxe, « Notas sobre cooperativismo, gestão rural, e bem viver na Amazônia: estratégias de resistência ao capitalismo », Configurações [Online], 25 | 2020, posto online no dia 21 junho 2020, consultado o 10 dezembro 2020. URL : http://journals.openedition.org/configuracoes/8562 ; DOI : https://doi.org/ $10.4000 /$ configuracoes.8562 
Witkoski, Antônio Carlos; Rezende, Marília Gabriela Gondim; Fraxe, Therezinha de Jesus Pinto - Notas sobre cooperativismo, gestão rural, e bem viver na Amazônia: estratégias de resistência ao capitalismo. Configurações, vol. 25, 2020, pp. 88-96.

\title{
Notas sobre cooperativismo, gestão rural, e bem viver na Amazônia: estratégias de resistência ao capitalismo
}

\author{
ANTÔNIO CARLOS WITKOSKI* \\ Universidade Federal do Amazonas, Brasil \\ MARÍLIA GABRIELA GONDIM REZENDE ** \\ Universidade Federal do Amazonas, Brasil \\ THEREZINHA DE JESUS PINTO FRAXE *** \\ Universidade Federal do Amazonas, Brasil
}

\begin{abstract}
Resumo
A Amazônia vem sendo rediscutida na contemporaneidade, devido aos interesses que a permeiam. O desflorestamento, o aumento do uso de agrotóxicos, e a poluição são problemas frequentes diante do atual cenário político que o Brasil, sobretudo a Amazônia, estão imersos. Nesse contexto, os povos amazônicos têm construído estratagemas de reprodução social centrados na sustentabilidade e no bem viver. Uma das estratégias encontradas foi o cooperativismo, voltado a outros fins, distintos dos capitalistas. Pode-se inferir que há uma relação intrínseca entre o bem viver como paradigma de desenvolvimento e a solidariedade, configurando uma tríade conformadora do sistema ambiental amazônico.
\end{abstract}

Palavras-chave: Bem viver, sustentabilidade, cooperação, solidariedade.

\begin{abstract}
Notes on Cooperativism, Rural Management, and Good Living in Amazonia: Strategies for Resisting Capitalism

Amazonia has been rediscussed in contemporary times, due to the interests that permeate it. Deforestation, increased use of pesticides, and pollution are frequent problems in view of the current political scenario that Brazil, especially Amazonia, is immersed in. In this context, the Amazonian people have constructed social reproduction strategies focused on sustainability and good living. One of the strategies found was cooperativism, aimed at other purposes, different from the capitalists. It can be inferred that there is an intrinsic relationship between good living as a development paradigm and solidarity, configuring a triad that shapes the Amazonian environmental system.
\end{abstract}

Keywords: Good living, sustainability, cooperation, solidarity.

*E-mail: : acwitkoski@uol.com.br.

${ }^{* *}$ E-mail: mariliageoufam@gmail.com.

*** E-mail: tecafraxe@uol.com.br. 


\section{Résumé}

Notes sur le coopérativisme, la gestion rurale et le bien-vivre en Amazonie : stratégies de résistance au capitalisme

L'Amazonie a fait l'objet d'une nouvelle discussion aujourd'hui, en raison des intérêts qui l'imprègnent. La déforestation, l'utilisation accrue de pesticides et la pollution sont des problèmes fréquents compte tenu du scénario politique actuel dans lequel le Brésil, et en particulier l'Amazonie, est plongé. Dans ce contexte, les peuples amazoniens ont construit des stratégies de reproduction sociale axées sur la durabilité et le bien-vivre. L'une des stratégies trouvées a été le coopérativisme, visant d'autres fins, différentes des capitalistes. On peut en déduire qu'il existe une relation intrinsèque entre le bien-vivre en tant que paradigme de développement et la solidarité, configurant une triade qui façonne le système environnemental amazonien.

Mots-clés: Bien-vivre, durabilité, coopération, solidarité.

\section{Introdução}

Para compreender o tema elencado construímos a narrativa a partir de uma organização didático-pedagógica. Nesse sentido, escolhemos como categorias principais o cooperativismo, centrado em Veiga e Fonseca (2002), e a gestão rural com base em Kageyama (2008). Entretanto, para que haja a compreensão das categorias centrais, com proficuidade, tornou-se necessária a escolha de duas categorias subjacentes, que auxiliaram na explicitação da narrativa, que são globalização, em lanni (1996), e governança, em Biermann (2012).

Por se tratar de um tema complexo, tratamo-lo em sua complexidade, destacando os pontos de intersecção e de dissidência entre os principais cientistas que trabalham a temática. Compreender as nuances do cooperativismo significa evidenciar processos que o geraram e o aperfeiçoaram ao longo da história, com suas concepções paradoxais. Porém, antes de realçar suas características e seus constructos históricos é preciso vislumbrá-lo a partir da diacronia e da anacronia.

O processo de internacionalização da economia tem gerado impactos em todas as esferas da vida social, engendrando transformações socioprodutivas em múltiplos territórios e escalas (lanni, 1995; Santos, 2008). Esses fatores tornaram visível o desenvolvimento desigual e contraditório sob o qual as sociedades estão imersas no seio do capitalismo. Tais transformações refletiram, significativamente, na estruturação do circuito espacial produtivo e na emergência das bases do cooperativismo como estratagema contra-hegemônico 


\section{Procedimentos teórico-metodológicos}

A presente pesquisa foi desenvolvida sob o prisma da complexidade sistêmica, preconizada por Morin (2015). Trata-se de um novo paradigma norteador da percepção e das análises dos sujeitos epistêmicos na contemporaneidade, e envolve tanto uma abordagem teórica de elucidação da complexidade, em suas múltiplas facetas, até uma reflexão na percepção dos elementos que compõem o sistema ambiental.

O artigo alicerçou-se em uma pesquisa bibliográfica, que é um tipo de pesquisa onde o sujeito epistêmico executa um levantamento de estudos científicos publicados em revistas, livros, teses, dissertações, dentre outros. Após a filtragem dos trabalhos, elabora-se um banco de dados, condensando todas as pesquisas encontradas, para a posterior sistematização (Treinta et al., 2014). Portanto, esse artigo foi construído a partir de uma miscelânea de trabalhos, produzidos por cientistas que pensam a Amazônia por meio de diferentes olhares epistemológicos e paradigmáticos. Além disso, foram sistematizados relatórios técnicos de órgãos governamentais e não-governamentais.

\section{0 cooperativismo como estratégia contrahegemônica}

O cooperativismo surgiu no circuito do capital, como uma ferramenta do capitalismo que visava o controle das massas trabalhadoras e a reprodução ampliada do capital (Rios, 1989). Todavia, apesar de ter surgido nesse contexto, o cooperativismo foi se metamorfoseando e servindo a outros interesses, distintos dos capitalistas. Arruda (2010) aponta que o cooperativismo consiste em um sistema de cooperação econômica cujo enredo se desenha nas facetas das formas de produção, de comercialização, de trabalho, e em vários setores da economia. Pode ser visualizado tanto na agricultura latifundiária como na agricultura familiar, o que evidencia o paradoxo sob o qual estamos nos referindo neste artigo.

Dessa forma, pode-se observar que o sistema de cooperação econômica pode ser encontrado tanto em uma empresa capitalista como em formas não tipicamente capitalistas de produção. Para explicitar seus constructos apresentaremos algumas características que conformam o cooperativismo e o materializam. A primeira delas é que enquanto o cooperativismo apresenta-se como um sistema, as cooperativas emergem como uma unidade econômica (Arruda, 2010).

Segundo, o capital social. Diferentemente dos ideais capitalistas, é um meio e não uma finalidade, é um fator de produção e não de renda financeira (Gawlak, 2007). De modo geral, o cooperativismo possui três características marcantes: a gestão da propriedade, os ideais, e a repartição das sobras cooperativas. Ou seja, enquanto que o objetivo do capitalismo é o lucro, dentre outros, no cooperativismo 
é a repartição das sobras cooperativas e o pleno desenvolvimento dos sujeitos sociais envolvidos.

Partindo dessa contextualização é importante destacar que o entendimento dos elementos que estruturam o cooperativismo perpassa, no campo, o vislumbre da gestão rural e os seus desdobramentos no território, tópicos específicos deste artigo. Assim sendo, visando facilitar a apresentação didática do texto, evidenciaremos os pontos que levam à intersecção analítica entre a gestão rural e o cooperativismo. A gestão rural envolve uma ampla gama de conhecimentos e de ações, devido à complexidade de gerir elementos e processos no mundo rural.

Envolve cosmologias particulares, ontologias diferenciadas, e aspectos culturais que tornam a gestão rural imprescindível diante de qualquer inferência ou desenvolvimento analítico do cooperativismo. Nesse sentido, falar de gestão rural significa explicitar variáveis controláveis como um elo do desenvolvimento rural. Significa desvelar a complexidade que a permeia e analisá-la sistematicamente, diante de questões endógenas e exógenas.

Por envolver questões de poder, afirma-se que essa gestão ocorre em um território, conjugador de materialidades e imaterialidades (Saquet, 2004; Raffestin, 1993; Gottmann, 1973). O território expressa os processos históricos que o constituíram e que o constituem, dialeticamente, por isso não podem estar à mercê dos processos mais amplos do rural amazônico. É por meio dele que se pode vislumbrar os processos sociopolíticos que antecederam a conformação e coadunaram o substrato material de reprodução humana e social dos sujeitos que cristalizam suas narrativas no espaço, transformando-o em território.

O território, por sua vez, pode ser tanto um instrumento do capitalismo (circuito espacial produtivo segregador) como uma ferramenta do desenvolvimento e base da economia solidária (Singer, 1998). O cooperativismo reaparece, nesse contexto, como um elo que pode ser utilizado para firmar alguns valores basilares da sustentabilidade ambiental, como a solidariedade e a cooperação. Isso envolve uma outra leitura de mundo, um novo olhar paradigmático capaz de modificar a relação com a natureza.

Maturana e Varella (2004) apontam em suas obras que essa nova relação pode ser explicitada por meio da concepção de autopoiese, que significa auto-produção. Por exemplo, os sistemas vivos são autopoiéticos, isto é, se auto produzem. Uma árvore, em seu processo natural de desenvolvimento, solta suas folhas, essas servem de adubo. Essa interação incessante evidencia a autopoiese e seus desdobramentos.

Nesse contexto, sabe-se que a gestão rural deve-se pautar na sustentabilidade, como princípio da resiliência (Veiga, 2007; Cavalcanti, 2012) para que as gerações atuais e futuras construam suas narrativas históricas em novas vias mais solidárias (Santos, 2008), centradas em aspectos da cortesia e da cordialidade, na Terra-Pátria (Morin, 2015). Para isso é necessário que seja repensada a governança sob a qual as 
sociedades vivem, deixando de ser uma governança unicamente estatal para dar voz a outras formas de organização social (Biermann, 2012).

Há governanças que partem de um apriorismo estatal e governanças que são tecidas sem centralidades e hierarquias, que partem do reconhecimento de que todos os elos são imprescindíveis para o desenvolvimento da sociedade, na perspectiva que Foucault (1987) denominou de genealogia do poder. Cabe destacar que o cooperativismo transporá seu próprio paradoxo, diante dessa contextualização. Ou servirá como instrumento da reprodução ampliada de capital de um desenvolvimento segregador e desigual, característico de uma governança autocrática, ou servirá como uma ferramenta de um desenvolvimento alternativo, pautado na resiliência ecossistêmica e na sustentabilidade ambiental, tecida em uma governança que expressa uma genealogia do poder.

\section{Cooperativismo, gestão rural e bem viver}

Há inúmeros artigos científicos e livros publicados reveladores de que o cooperativismo pode servir para criar as bases de uma contra-hegemonia, visualizada nos alicerces de um novo paradigma de desenvolvimento, o bem viver (Alcântara e Sampaio, 2017). O bem viver é tanto uma práxis como um paradigma em construção, e envolve uma nova relação com os recursos naturais, compreendendo-os como bens comuns (Ricoveri, 2012).

A Organização das Cooperativas Brasileiras (OCB) aponta a existência de, aproximadamente, 16 cooperativas no estado do Amazonas indicando a eficiência no desenvolvimento do cerne do cooperativismo na atualidade. Destacam-se, nesse contexto:

- a Cooperativa dos Produtores Rurais e Beneficiadores de Frutas Regionais do Município de Anori (Coopfrutas Anori), que produz, anualmente, cerca de 50 toneladas de açaí;

- a Cooperativa dos Criadores de Abelhas Indígenas da Amazônia (Coopmel), localizada no município Boa Vista do Ramos, que comercializa quase três toneladas de mel, por ano;

- a Cooperativa Mista de Desenvolvimento Sustentável e Economia Solidaria da Reserva Extrativista do Médio Juruá (CODAEMJ), localizada em Carauari, envolvida na coleta de sementes, realizada por 400 famílias.

Evidencia-se, com base nas assertivas acima, que o cooperativismo se vem expandindo no estado do Amazonas, devido aos benefícios que promove aos sujeitos envolvidos, e à facilidade em acessar políticas públicas assentadas na lógica da cooperação. Pode-se afirmar que o cooperativismo vem colaborando na materialização de uma economia alternativa, cuja base é a solidariedade, a cooperação, a sustentabilidade, e o bem viver. Dessa forma o cooperativismo, se pautado no bem viver e na economia solidária, pode firmar as bases para um desenvolvimento 
diferenciado, no que Sen (2010) denomina de desenvolvimento como liberdade. Há, portanto, uma complexa interação entre elementos cônjuges que se interligam na teia da sustentabilidade e do bem viver. Conformam-se, assim, os pilares de uma governança alternativa, explicitadora de novos olhares paradigmáticos e epistemológicos da gestão rural que, se bem trabalhada, pode se transformar em uma gestão diferenciada, neguentrópica, como será aludido posteriormente. A Figura 1 apresenta a importância do cooperativismo como engrenagem da sustentabilidade ambiental.

Figura 1: Cooperativismo e sustentabilidade ambiental

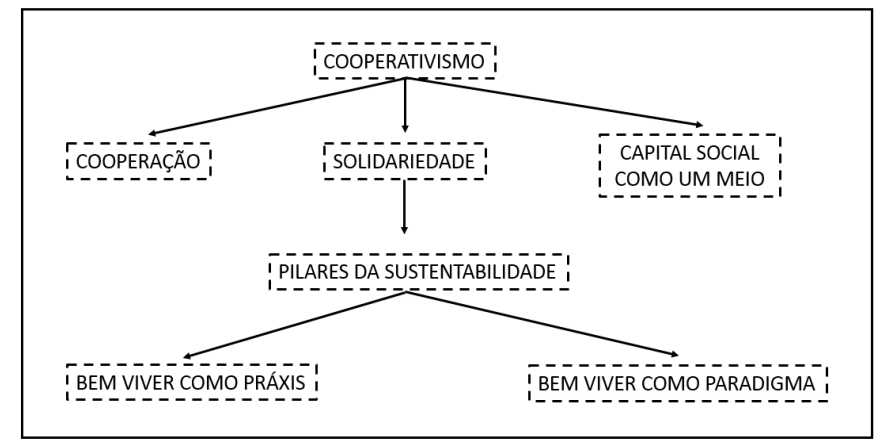

Fonte: Os autores, 2019

Após a observação do fluxograma, pode-se afirmar que há uma interdependência entre as variáveis apresentadas de modo que é impossível hierarquizá-las, pois só podem ser desveladas sob o prisma da complexidade sistêmica e da interdependência. Sendo assim, a partir desse entendimento, podemos avançar no desvelamento do que Leff denomina gestão neguentrópica, uma face da gestão rural que pode ser desvelada sob esses preceitos.

Para Leff (2001) neguentropia significa reaproveitamento de energia, ou seja, da energia que sai do ambiente. Esse reaproveitamento pode ser compreendido a partir do exemplo a seguir. Na gestão rural da agricultura familiar na Amazônia há uma lógica produtiva desenvolvida a partir de um saber ambiental. Os agricultores utilizam o esterco no processo de adubação que, por sua vez, facilita o desenvolvimento das plantas, que servirão de alimentação para o gado que produziu o esterco. Isto é um exemplo de gestão neguentrópica, que ocorre em certos territórios na Amazônia.

Nos parágrafos anteriores destacámos a relação entre o cooperativismo, nos preceitos aqui explicitados, a sustentabilidade ambiental, o bem viver e o desenvolvimento como liberdade. Essa compreensão foi aqui destacada para que fosse possível construirmos didaticamente as congruências entre os elementos do cooperativismo e da gestão rural. Partindo dessas questões, podemos avançar 
apresentando e explicitando que a cooperação, base do cooperativismo, está intimamente ligada à base do que Acselrad (2002) denomina de justiça ambiental.

A justiça ambiental consiste em uma nova forma de valoração da natureza, em ações de resistência que visam a compreensão da dinâmica conflitual e de um novo viés de apropriação, uso e significação do território (Acselrad, 2002). Sabe-se que há ausência, muitas das vezes, de proteção jurídica e de ações preventivas e repressivas em face dos danos ambientais (Pozzetti e Mendes, 2014). Essas dinâmicas recorrem a uma releitura da própria noção de ambiente, deixando de ser algo estático para ser um complexo ambiental (Gliessman, 2001).

É preciso compreender que o sistema ambiental possui uma organização própria, autopoiética, que precisa ser respeitada e compreendida para que no futuro haja o substrato material necessário à reprodução social. Não se trata de catastrofismo, mas do reconhecimento da finitude dos recursos naturais, do avanço avassalador de um capital apátrida, e da prática de um desenvolvimento que se preocupa unicamente com a reprodução ampliada do capital. Ao invés de pensarmos nas dificuldades impostas pelo capitalismo, é preciso tornar visível o que está sendo invisibilizado (Santos, 2008) pelo capitalismo moderno, que são as formas alternativas de desenvolvimento e de gestão rural.

A agricultura familiar na Amazônia, por exemplo, foi apontada por muitos autores como fadada ao desaparecimento, mas a história e o presente nos ensinam que isso não aconteceu e não está acontecendo. Muito pelo contrário, os camponeses amazônicos têm construído estratégias para lutar contra esse movimento excludente, como o desenvolvimento do cooperativismo aliado a uma gestão rural centrada no bem viver de seus povos. Fraxe (2011) e Witkoski (2010) apontam que a ciência deve contribuir para a reprodução da agricultura familiar na Amazônia, para que haja perpetuação da identidade e da cultura dos camponeses que desenvolvem trabalhos nas terras, florestas e águas.

Tonneau e Sabourin (2011) sempre evidenciaram que a agricultura familiar é produto e produtora de um desenvolvimento rural diferenciado. Ela resiste e não deixa de lado as relações com o mercado (Lamarche, 1993), muito pelo contrário, o utiliza para sua própria reprodução, em uma complexa teia de interdependência da vida. O cooperativismo possui um papel fundamental nesse processo, que vai desde o apoio à transição agroecológica, por meio da difusão de seus valores, até ao desenvolvimento da segurança alimentar (Fraxe e Castro, 2015).

As estruturas de cooperação dariam espaço para a criação de redes de economia solidária, a partir da gestão rural integrada da agricultura familiar (Filho e Batalha, 2005). Essa congruência cooperativismo/gestão rural evidencia a intersecção entre as categorias principais e as categorias subjacentes, apresentadas no primeiro parágrafo deste artigo. 


\section{Considerações finais}

O cooperativismo é de suma importância para o bem viver dos povos amazônicos e para a sustentabilidade ambiental, pois por meio dos seus ideais e das cooperativas autogestionárias fundamentam as bases da economia solidária, contrahegemônica. Apesar de ser também utilizado no viés capitalista, o cooperativismo pode metamorfosear-se e servir a outros interesses e construir o alicerce de uma gestão rural democrática, participativa, tecida em novas vias mais solidárias.

As ciências ambientais desempenham um importante papel diante dessas circunstâncias. Pode-se usar a ciência para alavancar o processo destrutivo do capitalismo contemporâneo ou pode-se criar um quadro teórico-analítico diferenciado para trabalhar uma nova lente paradigmática e epistemológica, conformadora de um bem viver. Trata-se de um paradoxo que terá consequências marcantes, qualquer que seja a decisão tomada.

Espera-se que os processos decisórios reflitam os interesses da maioria, e que sejam centrados nos preceitos da justiça ambiental e do bem viver, para que as gerações futuras possam ter acesso aos alimentos saudáveis, à um ambiente conservado, e para que haja o reconhecimento da importância do saber ambiental e de seus desdobramentos. Trata-se, portanto, de um imbróglio que marcará a história da humanidade e caracterizará as ciências ambientais por uma longa fratura de tempo. Espera-se que haja a escolha por vias mais solidárias que evidenciem um desenvolvimento como liberdade.

Portanto, este artigo distancia-se de assertivas axiomáticas, esboça a necessidade premente de uma rediscussão do papel das ciências ambientais na atualidade, sem neofilias. A miríade epistemológica reflete a multiplicidade de paradigmas, hegemônicos e contra-hegemônicos, que coexistem, em um movimento incessante de construção e reconstrução do pensar as ciências ambientais diante desses constructos existentes.

\section{Referências bibliográficas}

ACSELRAD, H. (2002), "Justiça ambiental e a construção social do risco, Desenvolvimento e Meio Ambiente, v. 5, p. 49-60.

ALCÂNTARA, L. C.; SAMPAIO, C. A. C. (2017), Bem viver como paradigma de desenvolvimento: utopia ou alternativa possível?, Revista Desenvolvimento e Meio Ambiente, Vol. 40, 231-251.

ARRUDA, M. (2010), Globalização e desenvolvimento local autogestionário.

BIERMANN, F. (2012), Global environmental governance: conceptualization and examples.

CAVALCANTI, C. (2012), Sustentabilidade: mantra ou escolha moral?, Revista Estudos Avançados, 26 (74).

FILHO, H. M. S.; BATALHA, M. O. (2005), Gestão integrada da agricultura familiar. Edufscar. FOUCAULT, M. (1987), Vigiar e punir, Petrópolis, Vozes.

FRAXE, T. J. P. (2011). Homens anfíbios: uma etnografia de um campesinato das águas. Annablume. FRAXE, T. J. P.; CASTRO, A. P. (2015). Agroecologia em sociedades amazônicas. Manaus, Editora \& Gráfica Moderna. 
GAWLAK, A. (2007), Cooperativismo: primeiras lições, Brasília, Sescoop.

GLIESSMAN, S. R. (2001), Agroecologia: processos ecológicos em agricultura sustentável, Porto Alegre, Ed. da UFRGS.

GOTTMANN, J. (1973), The significance of territory, Charlottesville Va., University Press of Virginia. IANNI, O. (1996), A era do globalismo, Rio de Janeiro, Civilização Brasileira.

IANNI, O. (1995), Teorias da globalização, Rio de Janeiro, Civilização Brasileira.

KAGEYAMA, A. A. (2008), Desenvolvimento rural: conceito e aplicação ao caso brasileiro, Porto Alegre, UFRGS Editora.

LAMARCHE, H. (1993), A agricultura familiar: uma realidade multiforme, Campinas, Editora da Unicamp.

LEFF, E. (2001), Epistemologia ambiental, São Paulo, Cortez.

LEFF, E. (2001), Saber ambiental, Rio de Janeiro, Vozes.

MATURANA, R; VARELLA, F. G. (2004), A árvore do conbecimento: as bases biológicas do conbecimento humano, Porto Alegre, Palas Athenas.

MORIN, E. (2015), O método 1: a natureza da natureza, São Paulo, Editora Sulina.

MORIN, E. (1995), Terra-Pátria, São Paulo, Editora Sulina.

POZZETTI, V. C.; MENDES, M. L. S. (2014), Biopirataria na Amazônia e a ausência de proteção jurídica, Revista Direito Ambiental e sociedade, v. 4.

RAFFESTIN, C. (1993), Por uma Geografia do Poder (Tradução de Maria Cecília França), São Paulo (SP), Ática.

RICOVERI, G. (2012), Bens comuns versus mercadoria, Rio de Janeiro, Multifoco.

RIOS, G. S. L. (1989), O que é cooperativismo? , São Paulo, Brasiliense.

SANTOS, B. S. (2008), Um discurso sobre as ciências, São Paulo, Cortez.

SANTOS, M. (2008), Por uma outra globalização: do pensamento único à consciência universal, Rio de Janeiro, Record.

SAQUET, M. A. (2004), As diferentes abordagens do território", In RIBAS, A.D.; SPOSITO, E.S.; SAQUET, M.A. (Org.), Território e desenvolvimento: diferentes abordagens, Francisco Beltrão: Unioeste.

SEN, A. (2010), Desenvolvimento como liberdade, São Paulo, Companhia das Letras.

SINGER, P. (1998), Uma utopia militante, Rio de Janeiro, Vozes.

TONNEAU, J. P.; SABOURIN, E. (2011), A agricultura familiar: interação entre políticas públicas $e$ dinâmicas locais.

TREINTA, F. T.; FILHO, J. R. F.; SANT'ANNA, A. P.; RABELO, L. M. (2014), Metodologia de pesquisa bibliográfica com a utilização de método multicritério de apoio à decisão, Production, v. 24, n. 3, p. 508-520.

VEIGA, J. E. (2007), A emergência socioambiental, São Paulo, Editora SENAC.

VEIGA, S. M.; FONSECA, I. (2002), Cooperativismo: uma revolução pacífica em ação, Rio de Janeiro, DP\&A/Fase.

WITKOSKI, A. C. (2010), Terras, florestas e águas de trabalbo: os camponeses amazônicos e as formas de uso de seus recursos naturais, Annablume. 